\title{
The Clinical and Biochemical Parameter Data: Effect of High Blood Glucose on Diabetic Nephropathy Among Non-Insulin- Dependent Diabetes Mellitus (NIDDM), Thailand
}

\author{
Chitkamon SRICHOMPOO ${ }^{\mathrm{a}}$, Warantorn POTARIN ${ }^{\mathrm{b}}$, Supattra NOO-In ${ }^{\mathrm{c}}$, \\ Patcharin PHUWILERT ${ }^{\mathrm{c}}$ and Santisith KHIEWKHERN ${ }^{\mathrm{c}, 1}$ \\ a Mahachanachai Hospital, Yasothorn, Thailand \\ ${ }^{b}$ Srimahasarakham Nursing collage, Faculty of Nursing, Praboromarajchanok, \\ Thailand \\ ${ }^{c}$ Faculty of public health, Mahasarakham University, Thailand
}

\begin{abstract}
Background: Diabetic nephropathy (DN) is one of the long-term complications of patients with type 2 diabetes. The leading causes of DN are high blood glucose and hyper systolic blood pressure. Methods: A retrospective cohort study was performed to explore the effects of high blood sugar and hyper systolic blood pressure on DN among 660 non-insulin-dependent diabetes mellitus. Data was collected from the HosXP program and medical records from 2016 to 2020. The Forest plot was used to examine the effect of hypertriglyceridemia and hyper systolic blood pressure with DN. Results: The results confirmed that the factors associated with $\mathrm{DN}$ were male, age $\geq 60$ years, diabetic duration $\geq 10$ years, systolic $\mathrm{BP} \geq 130 \mathrm{mmHg}$, and $\mathrm{HbAlc} \geq 6 \%$. Conclusion: The health promotion program should be comprised of the control of blood glucose and systolic blood pressure procedure especially male patients with age $\geq 60$ years and diabetic duration $\geq 10$ years.
\end{abstract}

Keywords. Chronic kidney disease, albuminuria, glomerular filtration rate, diabetic duration

\section{Introduction}

Diabetic nephropathy (DN) is one of the long-term complications of patients with both type 1 and type 2 diabetes mellitus. Diabetic nephropathy affects the function of kidney failure to remove waste products and superfluous fluid from the body. The leading causes of DN are hypertriglyceridemia and hyper systolic blood pressure [1,3]. The best way to prevent or delay diabetic nephropathy is by maintaining a healthy lifestyle and controlling blood glucose and blood pressure. In this study, the effects of hypertriglyceridemia and hyper systolic blood pressure on diabetic nephropathy among

${ }^{1}$ Corresponding Author, Santisith Khiewkhern, Faculty of Public Health, Mahasarakham University, Thailand; 44150. E-mail: santisith.k@msu.ac.th. 
Thai patients with non-insulin-dependent (NIDDM) are explored for the improved management of this disease.

\section{Methods}

Study design: A retrospective cohort study was used to examine the effects of hypertriglyceridemia and hyper systolic blood pressure to diabetic nephropathy among Thai patients with non-insulin-dependent.

Population: The population included 2,303 type non-insulin dependent diabetes mellitus who attended the diabetes care clinic of Mahachanachai Hospital, Yasothorn Province in the North-East region of Thailand. The characteristics, clinical and biochemical data of the patients were recorded during the period from October 1st, 2016 to September 30th, 2020.

Sample: 660 eligible cases of type non-insulin dependent diabetes mellitus attending the diabetes care clinic of Mahachanachai Hospital, Thailand.

Inclusion criteria: Inclusion criteria included patients with type 2 diabetes over the age of 18 years, free of DN and free from diabetic complications like retinopathy, neuropathy, peripheral vascular disease, or coronary artery disease at baseline.

Exclusion criteria: Exclusion criteria were type 2 diabetes patients who had additional complications approximating retinopathy, neuropathy, peripheral vascular disease, or cardiovascular disease during the follow up period and who did not have complete data for kidney diseases assessment and patients who did not have complete data regarding the biochemical parameter such as, triglyceride and systolic blood pressure.

Outcome measures: The identification of DN in type 2 diabetes patients was based on the Thai National Kidney Foundation 2002 criteria for diagnosis, which used an eGFR of less than $60 \mathrm{ml} / \mathrm{min} / 1.73 \mathrm{~m} 2$, a urinary albumin/creatinine ratio (UACR) of $30-300 \mathrm{mg} / \mathrm{g}$, or positive Microalbuminuria dipstick test $\geq 1+$ the same criteria as followed in the other studies [2,3].

Data collection: This study used secondary data which collected from the HosXP program and medical records from 2016 to 2020 at Mahachanachai Hospital, Thailand.

Statistical analysis: Descriptive statistics were used to define the characteristics of the subjects. The $95 \%$ CI of adjusted OR from multiple logistic regressions were used to examine the effects of hypertriglyceridemia and hyper systolic blood pressure with DN. Backsword method was used to examine risk factors of DN. These effects were presented by the forest plot.

Ethic Declarations: Approval from the Ethics Committee for Research Involving Human Subjects of Mahasarakham University, Thailand was attained before the study was carried out (PH057/2561). The information of respondents that was obtained through medical records and medical electronic data were kept confidential and anonymous.

\section{Results}

The results from the multiple logistic regression with a backward method confirmed that the factors associated with diabetic nephropathy were male, age $\geq 60$ years, diabetic duration $\geq 10$ years, systolic $\mathrm{BP} \geq 130 \mathrm{mmHg}$, and high blood sugar ( $\mathrm{HbAlc} \geq 6 \%$ ). 
However, smoking and alcohol consumption were not statistically significantly associated with DN (Table 1).

Table 1 Factors associated with DN.

\begin{tabular}{ccccc}
\hline \multirow{2}{*}{ Factors } & \multirow{2}{*}{ adjusted OR } & \multirow{2}{*}{ P-value } & \multicolumn{2}{c}{ 95\%CI of OR } \\
\cline { 4 - 5 } & & & Lower & Upper \\
\hline male & 1.69 & .003 & 1.28 & 2.14 \\
age $\geq 60$ years & 1.58 & .005 & 1.18 & 2.00 \\
diabetic duration $\geq 10$ years & 1.35 & .008 & 1.04 & 1.92 \\
BP $\geq 130$ mmHg & 1.41 & .025 & 1.06 & 1.80 \\
HbA1c $\geq 6 \%$ & 1.94 & .020 & 1.44 & 2.11 \\
\hline
\end{tabular}

The radar plot was created by using the adjusted OR from multiple logistic regression with a backward method to examine risk factors of DN. The results showed that high blood sugar ( $\mathrm{HbAlc} \geq 6 \%$ ) is a higher effect on $\mathrm{DN}$, the second is male and follow by age $\geq 60$ years, $\mathrm{BP} \geq 130 \mathrm{mmHg}$, and diabetic duration $\geq 10$ years. Figure 1 .

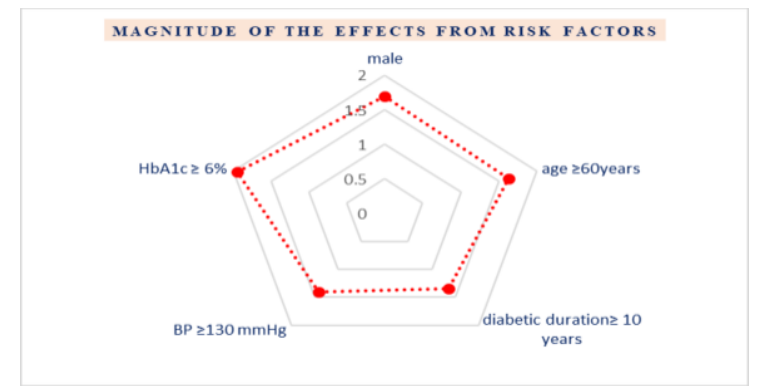

Figure 1 Radar plot present the magnitude of the effect from risk factors to DN.

The adjusted OR and 95\%CI of OR were used to create the Forest plot. A Forest plot was used to explain approximately the accuracy of the effect of risk factors on DN. The results showed that the effect of high blood sugar $(\mathrm{HbAlc} \geq 6 \%)$ is the most far from 1 and followed by male (HbA1c $\geq 6 \%)$ Figure 2 .

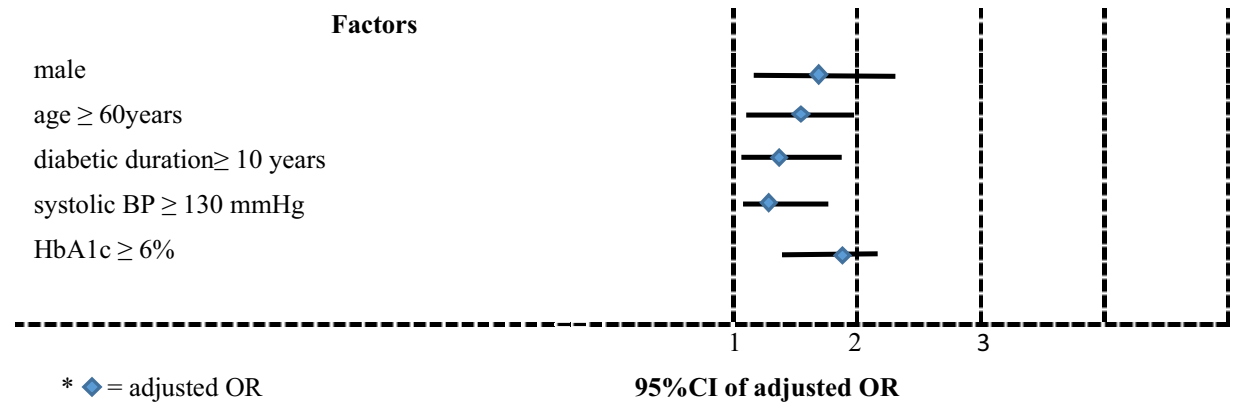

Figure 2. Forest Plot of $95 \% \mathrm{CI}$ of adjusted OR.

\section{Discussion}

The results confirmed that the significant factors associated with diabetic nephropathy were male, age $\geq 60$ years, diabetic duration $\geq 10$ years, systolic $\mathrm{BP} \geq 130 \mathrm{mmHg}$, and high blood glucose level $(\mathrm{HbA} 1 \mathrm{c} \geq 6 \%)$ are the high magnitude and strongest 
associated with DN in non-insulin-dependent diabetes mellitus patients. These results are similar to previous studies of Elmarakby et al. [1] and Alrawahi et al. [4]. High blood sugar levels can damage the small blood vessels of the nephron especially those who cannot control blood sugar for a long time [1,5]. In addition, the blood vessels of the elderly patients must be weekend by age [5] including quite a lot of patients with diabetes who also have high blood pressure, which can cause damage to blood vessels of the nephron [4]. All so, blood pressure is the strength of blood pushing against blood vessels, including in the kidneys. When the blood vessels in the kidneys are damaged, this stretching weakens blood vessels in the nephron, they cannot function to remove wastes and extra fluid from the body. However, smoking and alcohol consumption were not statistically significantly associated with DN could be due to inequalities in several factors including study design, source of population, definition, and suitable information.

\section{Conclusions}

The screening approaches should be emphasized especially in male patients and those with age more than 60 years including duration of diabetes $\geq 10$ years. Control of blood sugar and systolic blood pressure should be included in health promotion programs for the patients to result in delaying nephropathy in non-insulin-dependent diabetes mellitus patients.

\section{Acknowledgments}

We would like to thank you the nurses and doctors at the Diabetic Care Centre in Mahachanachai Hospital, Thailand. This study was supported by the Faculty of Public Health, Mahasarakham University, and Mahachai Hospital, Thailand.

\section{References}

[1] Elmarakby AA, Sullivan JC. Relationship between oxidative stress and inflammatory cytokines in diabetic nephropathy. Cardiovasc Ther. 2012 Feb;30(1): 49-59.

[2] National Kidney Foundation. K/DOQI clinical practice guidelines for chronic kidney disease: evaluation,classification, and stratification. Am J Kidney Dis Off J Natl Kidney Found. 2002;39(2 Suppl 1):S1-266.

[3] Khiewkhern S, Yoosook W, Srichomphoo C, Thongkum W, Thitisutthi S. Risk Factors of Diabetic Nephropathy Development in Type 2 Diabetic Patients: A Cross-sectional Retrospective Study. Journal of Clinical and Diagnostic Research. 2021;15(2):7-12.

[4] Alrawahi AH, Rizvi SG, Al-Riyami D, Al-Anqoodi Z. Prevalence and risk factors of diabetic nephropathy in omani type 2 diabetics in Al-dakhiliyah region. Oman medical journal. 2012 May;27(3):212.

[5] Juraschek SP, Chang AR, Appel LJ, Anderson CAM, Crews DC, Thomas L, et al. Effect of glycemic index and carbohydrate intake on kidney function in healthy adults. BMC Nephrol. 2016 08;17(1):70. 